\title{
Laboratory Case Report
}

Beverley M. Pullon*

\section{An evaluation of glycated haemoglobin eluting in zone 10 on capillary zone electrophoresis}

https://doi.org/10.1515/labmed-2019-0136

Received August 5, 2019; accepted November 5, 2019; previously published online November 29, 2019

\begin{abstract}
This is the first report of glycated haemoglobin $(\mathrm{Hb})$ eluting in zone 10 on capillary zone electrophoresis (CZE). In an index case, the aberrant peak was picked up during routine haemoglobinopathy testing using CZE. Mass spectrometry (MS) revealed this aberrant peak to be glycated $\mathrm{Hb}$. Prompted by this initial case, a study was undertaken and the results showed that there was a strong positive linear relationship $\left(R^{2}=0.774 ; \rho=0.88\right)$ between the level of glycated $\mathrm{Hb}$ peak eluting in zone 10 and the $\mathrm{HbA}_{1 \mathrm{c}}$ value. Furthermore, all samples with an $\mathrm{HbA}_{1 \mathrm{c}}$ of $54 \mathrm{mmol} / \mathrm{mol}$ or greater had an $\mathrm{HbA}_{1 \mathrm{c}}$ peak eluting in zone 10.
\end{abstract}

Keywords: capillary zone electrophoresis; glycated haemoglobin; $\mathrm{HbA}_{1 c}$; zone 10 peaks.

Brief summary: A previously undescribed haemoglobin $(\mathrm{Hb})$ peak in zone 10 on capillary zone electrophoresis (CZE) was evaluated and shown to be glycated $\mathrm{Hb}$. A linear relationship between the percentage of glycated $\mathrm{Hb}$ peak and $\mathrm{HbA}_{1 \mathrm{c}}$ value was demonstrated. The threshold for detection of glycated $\mathrm{Hb}$ eluting in zone 10 is an $\mathrm{HbA}_{1}$ value of $54 \mathrm{mmol} / \mathrm{mol}$.

\section{Introduction}

Capillary zone electrophoresis (CZE) is becoming routinely used in clinical laboratories as a reliable method for the detection of haemoglobinopathies (haemoglobin [Hb] variants and thalassaemias). The CZE assay separates the $\mathrm{Hb}$ fractions in silica capillaries by their electrophoretic mobility and electro-osmotic flow at a high voltage in an alkaline buffer. The $\mathrm{Hb}$ fractions are directly detected at the specific

\footnotetext{
*Correspondence: Beverley M. Pullon, Haematology Laboratory, Waikato District Health Board, Pembroke Street, Private Bag 3200, Hamilton 3204, New Zealand, E-Mail: beverley.pullon@waikatodhb. health.nz. https://orcid.org/0000-0002-3863-5605
}

absorbance wavelength of $415 \mathrm{~nm}$. A grid divides the $\mathrm{Hb}$ migration into 15 zones on the $\mathrm{x}$-axis from 0 to 300, with $\mathrm{HbA}$ standardised to migrate at position 150 [1]. Hb variants are delineated by their electrophoretic mobility and specific zone positions. A chart describing the $\mathrm{Hb}$ variants associated with each zone is available [1, 2].

During routine haemoglobinopathy testing on the newly introduced Capillary 2 Flex Piercing (with $\mathrm{Hb}$ variant programme) instrument in our clinical laboratory, we observed a $2 \% \mathrm{Hb}$ peak eluting in zone 10 at migration position 137, in a patient sample. Comparison with published literature failed to identify this aberrant peak. Subsequent mass spectrometry (MS) testing revealed this aberrant peak to be glycated $\mathrm{Hb}$ a finding that has not previously been reported.

After this index case was confirmed as glycated $\mathrm{Hb}$, we observed a similar $\mathrm{Hb}$ peak of $\leq 2.0 \%$ eluting in zone 10 on further samples during haemoglobinopathy testing using CZE. This prompted an in-depth study with two aims: firstly, to investigate whether there was a relationship between the percentage of glycated $\mathrm{Hb}$ eluting in zone 10 and the $\mathrm{HbA}_{1 c}$ value, and secondly, to determine whether there was a threshold level of glycated $\mathrm{Hb}$ which would cause the observed zone 10 peak.

\section{Case presentation}

The initial subject of this investigation was a 15 -year-old female of New Zealand Mōori ethnicity. A haemoglobinopathy screen was requested due to thalassaemic indices in her full blood count: $\mathrm{Hb} 110 \mathrm{~g} / \mathrm{L}$, red blood cells (RBC) $4.64 \times 10^{12}$, mean corpuscular volume (MCV) $73 \mathrm{fl}$, mean corpuscular haemoglobin (MCH) $24 \mathrm{pg}$, red cell distribution width (RDW) 17.0\%. White cell count and platelets were normal.

CZE was performed using the $\mathrm{HbE}$ programme on a Sebia Capillarys 2 Flex Piercing analyser (Sebia, Lisses, France). The manufacturer's guidelines were followed when performing the analysis. A slightly low $\mathrm{HbA}_{2}$ of $2.1 \%$ (normal range $=2.2-3.3 \%$ ) and a normal $\mathrm{HbF}<1 \%$ (normal range $=<1 \%$ ) were present. In addition, an aberrant peak 


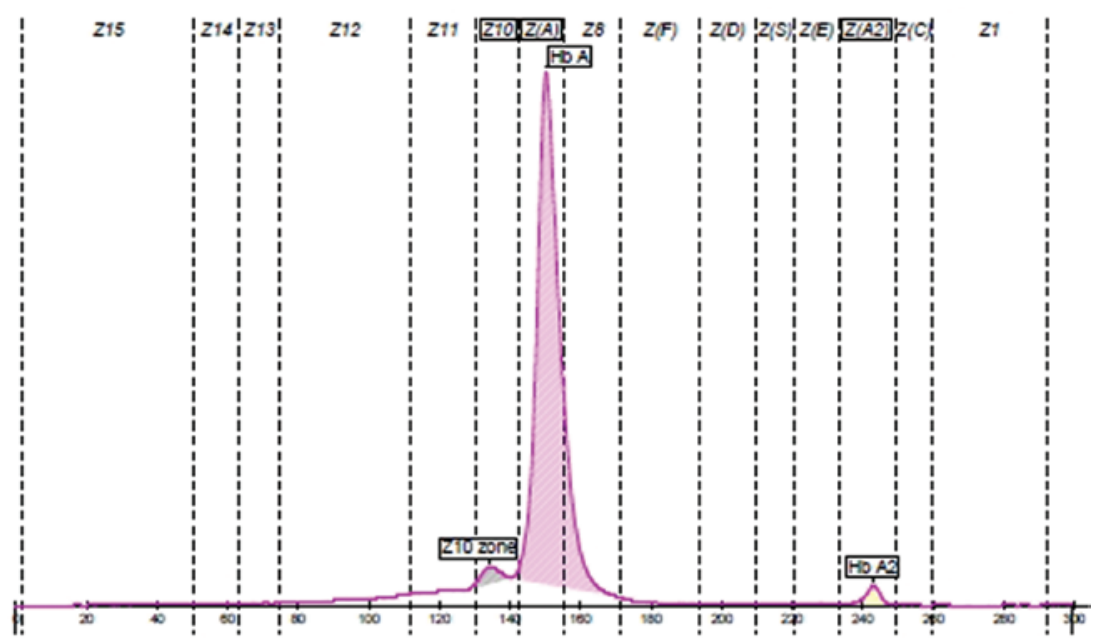

\section{Haemoglobin Electrophoresis}

\begin{tabular}{lcc} 
Name & $\%$ & Normal Values \% \\
\hline Z10 zone & 2.0 & \\
Hb A & 95.9 & \\
Hb A2 & 2.1 &
\end{tabular}

Figure 1: Capillarys Hemoglobin(E) Electrophoresis chromatogram showing the zone 10 peak of $2.0 \%$ eluting just before $\mathrm{HbA}_{0}$.

constituting $2.0 \%$ was detected in zone 10 (Figure 1 ). $\alpha$-Thalassaemia testing performed using the immunochromatographic (IC) strip test for $\alpha$-thalassaemia ( $i+$ Med Laboratories, Bangkok, Thailand) was positive.

To establish the identity of the zone 10 peak, further investigations were undertaken. Hb electrophoresis was performed on cellulose acetate at $\mathrm{pH} 8.5$ using the Sebia Hydragel Hemoglobin(E) kit and stained with amidoblack. This revealed the presence of two major bands: one with the mobility of $\mathrm{HbA}$ and the other a fast band running ahead of $\mathrm{HbA}$.

Examination of lysate by electrospray ionisation (ESI) MS on an Agilent 6230 time-of-flight instrument [3] (Agilent Technologies, Santa Clara, CA, USA) showed a normal pattern of $\alpha$ and $\beta$ chains but with very high levels of glycation at $+162 \mathrm{Da}$ (Figure 2). The mass increase of $162 \mathrm{Da}$ is due to the addition of glucose (180 Da) minus water $(-18 \mathrm{Da})$ [4].

An $\mathrm{HbA}_{1 \mathrm{c}}$ assay undertaken on a Bio-Rad D100 HPLC system (Hercules, CA, USA), performed on the same day as her haemoglobinopathy screen was markedly raised at $>166 \mathrm{mmol} / \mathrm{mol}$, consistent with a history of poorly controlled type 1 diabetes mellitus.

The subsequent study used patient samples which had been tested concurrently for both haemoglobinopathy screening and $\mathrm{HbA}_{1 \mathrm{c}}$ quantitation. There were
154 samples; ages ranged from 7 to 91 years, with $75(48.7 \%)$ females and 79 (51.3\%) males. Seventy-three of 154 (47.4\%) samples yielded glycated $\mathrm{Hb}$ peaks between 0.1 and $2.0 \%$ eluting in zone 10 at migration position $136.5 \pm 1.0$ on CZE (Figure 3). The $\mathrm{HbA}_{1 \mathrm{c}}$ values ranged from 18 to $166 \mathrm{mmol} /$ $\mathrm{mol}$ with a median of $49 \mathrm{mmol} / \mathrm{mol}(\mathrm{nr}<40 \mathrm{mmol} / \mathrm{mol})$.

\section{Discussion}

This study reports the investigation of an aberrant zone 10 peak on CZE. To elucidate Hb variants known to elute in zone 10, the Sebia Capillarys Hemoglobin(E) Electrophoresis instruction manual [1] and Sebia website customer extranet Hemoglobin Atlas [2] were consulted. There were a total of eight listed: three $\alpha$-chain variants (Hb Nouakchott, $\mathrm{Hb}$ Wayne, $\mathrm{Hb}$ M-Iwate [M-Kankakee]) and five $\beta$ chain variants (Hb Camden [Tokuchi], Hb Hope, Créteil, $\mathrm{Hb}$ Complutence, Hb Stockholm). The chromatograms, percentage variant and $\mathrm{x}$-axis position were reviewed for the reported variants for which information was available. The zone 10 peak characterised in our index case, and in the samples further investigated, did not correlate with any of these reported variants. 


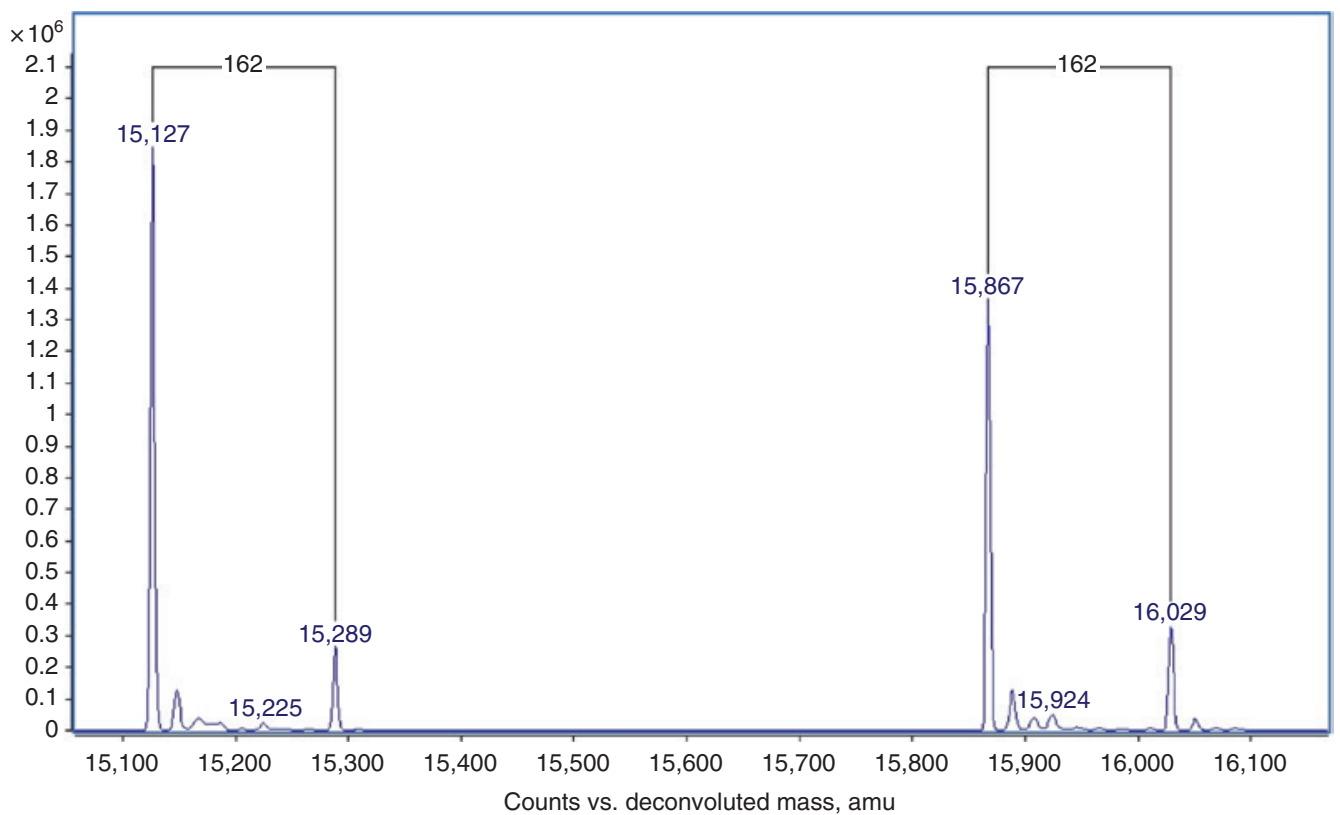

Figure 2: Transformed electrospray mass spectrum of whole lysate showing normal $\alpha$ and $\beta$ chains at 15,127 and 15,867 Da. Glycation causes a mass increase of $162 \mathrm{Da}$ and the glycated $\alpha$ and $\beta$ chains are shown at 15,289 and 16,029 Da, respectively.

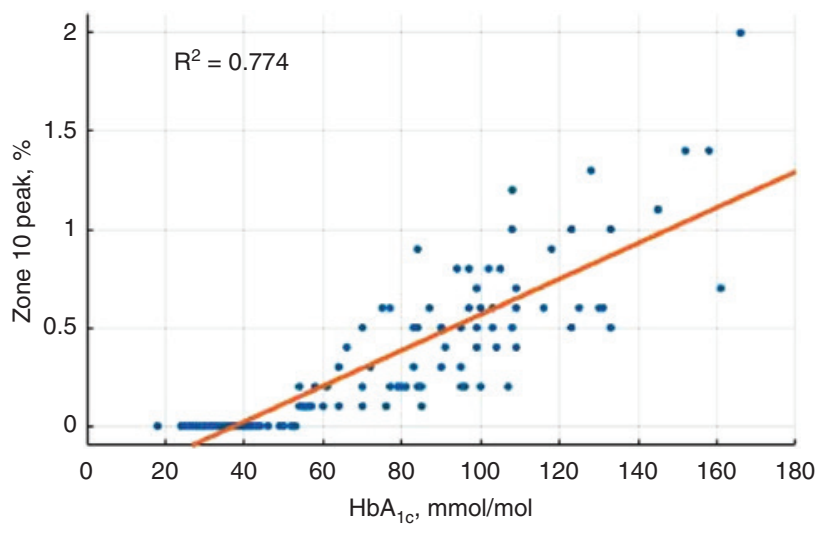

Figure 3: Graph showing the relationship between $\mathrm{HbA}_{1 c}$ value $(\mathrm{mmol} / \mathrm{mol})$ and percentage of peak in zone 10 for the 154 samples collected for this study.

MS determined the aberrant peak to be glycated $\mathrm{Hb}$. The major fraction of glycated $\mathrm{Hb}$, constituting approximately $80 \%$ of $\mathrm{HbA}$, is $\mathrm{HbA}_{1 \mathrm{c}}$ in which glucose is attached to the $\mathrm{N}$-terminal valine residue of the $\beta$ chain of $\mathrm{HbA}$ [5]. Glycation may also occur at sites other than the end of the $\beta$ chain, such as lysine residues or the $\alpha$ chain of $\mathrm{Hb}$. MS measures all types of glycated $\mathrm{Hb}$, whilst methods that measure $\mathrm{HbA}_{1 \mathrm{c}}$, such as the Bio-Rad D100, specifically measure glucose that is attached at the N-terminal valine [6]. Previous MS studies have established that every sample with an increased $\mathrm{HbA}_{1 c}$, i.e. observable $\beta$-chain glycation at the $\mathrm{N}$-terminal valine, also had $\alpha$-chain glycation [7]. Additionally, some samples had glycation at other $\beta$-chain glycation sites, such as lysine, as well. Furthermore, as glycation increased, the ratio of $\beta$-chain to $\alpha$-chain glycation increased, and the number of glycation sites on the $\beta$ chain increased [7]. This case had an elevated $\mathrm{HbA}_{1 \mathrm{c}}$ value corresponding to high glycation levels as measured by MS, representing $11 \%$ and $19.5 \%$ glycated $\alpha$ and $\beta$ chains, respectively, of the total $\alpha$ - and $\beta$-chain material. Based on the study by Peterson et al. [7], it seems reasonable to assume that the observed zone 10 peak may represent glycated $\mathrm{Hb}$ that has been glycated on other sites of the $\alpha$ and $\beta$ chains, not only $\mathrm{HbA}_{1 c^{\circ}}$.

Data from the investigation initiated by the index case showed the lowest level of glycated $\mathrm{Hb}$ eluting in zone 10 was $0.1 \%$. This level was associated with $\mathrm{HbA}_{1 c}$ values of $54,55,56,57,60,64,70,76$ and $85 \mathrm{mmol} / \mathrm{mol}$. The highest level of glycated $\mathrm{Hb}$ eluting in zone 10 was $2.0 \%$, which was associated with an $\mathrm{HbA}_{1 \mathrm{c}}$ level of $166 \mathrm{mmol} /$ mol. These results showed there was a strong positive linear relationship $\left(\mathrm{R}^{2}=0.774\right.$; Pearson's correlation coefficient $\rho=0.88$ ) between the percentage glycated $\mathrm{Hb}$ peak in zone 10 and the $\mathrm{HbA}_{1 \mathrm{c}}$ value.

All samples with an $\mathrm{HbA}_{1 \mathrm{c}}$ of $\geq 54 \mathrm{mmol} / \mathrm{mol}$ had a glycated $\mathrm{Hb}$ peak eluting in zone 10, this effect was not seen in $\mathrm{HbA}_{1 \mathrm{c}}$ levels of less than $54 \mathrm{mmol} / \mathrm{mol}$. This determined that an $\mathrm{HbA}_{1 \mathrm{c}}$ of $54 \mathrm{mmol} / \mathrm{mol}$ or greater was the threshold value that would produce the observed glycated $\mathrm{Hb}$ peak eluting in zone 10 on CZE (Figure 3). 


\section{Conclusions}

This report describes for the first time a glycated $\mathrm{Hb}$ peak eluting in zone 10 on CZE, demonstrating a strong positive linear relationship to the $\mathrm{HbA}_{1 \mathrm{c}}$ value. These results would suggest that if an $\mathrm{HbA}_{1 \mathrm{c}}$ value is less than $54 \mathrm{mmol} / \mathrm{mol}$, the zone 10 peak is unlikely to represent $\mathrm{HbA}_{1 \mathrm{c}}$ and could be indicative of an $\mathrm{Hb}$ variant.

Acknowledgments: Thanks to Prof. Stephen Brennan and Jordyn Moore, Canterbury Health Laboratories, for mutation analysis and Dr. Rebecca Pullon for statistical advice.

Author contributions: The author has accepted responsibility for the entire content of this submitted manuscript and approved submission.

Research funding: None declared.

Employment or leadership: None declared.

Honorarium: None declared.

Competing interests: The funding organisation played no role in the study design; in the collection, analysis, and interpretation of data; in the writing of the report; or in the decision to submit the report for publication.

\section{References}

1. Sebia: Capillarys Hemoglobin(E). Using the Capillarys 2 FlexPiercing Instrument. 2013/01. http://www.ilexmedical.com/files/ Sebia\%20inserts/CAPILLARYS_HEMOGLOBIN(E).pdf.

2. Sebia home page: https://extranet.sebia.com.

3. Brennan SO, Wang D, Horridge M, Sheen CR. Hb Amsterdam-A1 [ $\alpha 32$ (B13)Met $\rightarrow$ Ile; HBA1: c.99G > A]: a hyperunstable variant due to a new mutation on the $\alpha 1$ gene. Hemoglobin 2017;41:140-3.

4. Ho CS, Lam CW, Chan MH, Cheung RC, Law LK, Lit LC, et al. Electrospray ionisation mass spectrometry: principles and clinical applications. Clin Biochem Rev 2003;24:3-12.

5. Burtis CA, Ashwood ER, Bruns DE. Tietz textbook of clinical chemistry and molecular diagnostics. London: Elsevier Health Sciences, 2006.

6. Little RR, Roberts WL. A review of variant haemoglobins interfering with haemoglobin A1c measurement. J Diabetes Sci Technol 2009;3:446-51.

7. Peterson KP, Pavlovich JG, Goldstein D, Little R, England J, Peterson CM. What is hemoglobin A1c? An analysis of glycated hemoglobins by electrospray ionization mass spectrometry. Clin Chem 1998;44:1951-8. 